\title{
PENDAYAGUNAAN INTERNET SEBAGAI AKSIOLOGI BELAJAR PEMBELAJARAN ERA DIGITAL
}

\author{
Zahid Zufar At Thaariq \\ Universitas Negeri Malang \\ email: zahid.thoriq.1701216@students.um.ac.id
}

\begin{abstract}
Abstrak
Dunia yang serba digital telah mampu mempengaruhi semua bidang, termasuk pendidikan. Internet telah menjadikan hidup menjadi lebih mudah, termasuk dalam proses belajar yang dilakukan. Tulisan ini bertujuan untuk menyajikan pemecahan masalah belajar melalui pendayagunaan internet sebagai aksiologi belajar di era digital. Dalam ilmu filsafat dikenal dengan istilah ontologi, epistemologi dan aksiologi. Penggunaan internet saat ini telah menjadi suatu keniscayaan yang tidak dapat terhindarkan. Maka, dalam ranah filsafat hal ini disebut aksiologi yang berarti membahas tentang bagaimana seseorang menggunakan suatu keilmuan. Dalam bahasan ini akan menjurus ke ranah bagaimana seseorang menggunakan internet dalam belajar yang melibatkan pengajar dan pebelajar. Harapannya melalui tulisan ini dapat menjadi acuan referensi belajar maupun mengajar dengan memanfaatkan internet di dalamnya.
\end{abstract}

Kata Kunci: Internet; Aksiologi; Belajar dan Pembelajaran; Era Digital

\begin{abstract}
The digital world has been able to affect all fields, including education. The internet has made life easier, including in the learning process. This paper aims to present learning problem solving through the utilization of the internet as an axiology of learning in the digital era. In philosophy, it is known as ontology, epistemology and axiology. The use of the internet today has become an unavoidable necessity. So, in the realm of philosophy this is called axiology which means discussing how someone uses a science. In this discussion, it will lead to the realm of how someone uses the internet in learning that involves teachers and students. It is hoped that this article can become a reference for learning and teaching by using the internet in it.
\end{abstract}

Keywords: Internet; Axiology; Teaching and Learning; Digital Age

\section{PENDAHULUAN}

Perkembangan saat ini telah menjadikan adanya kemudahan dalam berbagai hal. Mulai dari bertransaksi hingga belajar dapat dilakukan secara mudah dengan menggunakan teknologi digital. Transformasi ini penting bagi sektor ritel yang mempengaruhi dan dipengaruhi oleh perkembangan tersebut. Pengecer menyediakan konsumen dengan berbagai produk dan layanan digital yang disesuaikan dengan penggunaan teknologi digital dan secara bersamaan dipengaruhi oleh bentuk konsumsi baru yang terkait dengan teknologi digital ini (Hagberg, Sundstrom, \& EgelsZandén, 2016). Ada banyak domain yang akan sangat diuntungkan dari digitalisasi, mulai dari artefak dan aset budaya (misalnya, karya seni, peninggalan sejarah, dan dokumen) dapat didigitalkan dan dilestarikan serta ditampilkan kepada massa, bahkan jika dicuri, dihancurkan, atau tidak dapat diakses secara langsung. Para ilmuwan sekarang dapat mendigitalkan eksperimen mereka, sehingga pengaturan dan hasil eksperimen mereka dapat diulang dengan lebih mudah untuk memungkinkan analisis 
dan pengawasan lebih lanjut (Gray \& Rumpe, 2015).

Dalam masyarakat modern dan lingkungan industri, sistem operasi organisasi menjadi semakin kompleks dan otomatis. Sistem ini terdiri dari orang, mesin, stasiun kerja, perangkat, robot, dan aset lainnya dengan pemantauan, sensor, dan sistem kontrol yang sesuai. Tantangan konstan dalam kaitannya dengan sistem ini adalah penyisipan teknologi baru, yang meliputi digitalisasi, seringnya perubahan dalam proses operasi, gangguan acak, dan permintaan pasar yang berfluktuasi secara dramatis (Parida, 2018). Sementara digitalisasi menekankan pada teknologi digital, istilah digitalisasi telah diciptakan untuk menggambarkan berbagai fenomena sosioteknik dan proses mengadopsi dan menggunakan teknologi ini dalam konteks individu, organisasi, dan masyarakat yang lebih luas (Legner dkk., 2017). Hal ini tidak terlepas dari adanya peran internet di dalamnya.

Pertumbuhan internet sangat spektakuler. Sekarang ada lebih dari 2 miliar pengguna internet di seluruh dunia, sekitar 30 persen dari populasi dunia. Ini tentu merupakan fenomena baru yang sangat berarti bagi kehidupan ekonomi, politik dan sosial masyarakat kontemporer (Curran, Fenton, \& Freedman, 2016). Untuk sebagian besar dari roda kehidupan, Internet adalah aktivitas individu yang dominan. Tidak seperti TV, yang dapat diperlakukan sebagai "kebisingan" latar belakang, TV membutuhkan lebih banyak keterlibatan dan perhatian. Meskipun sejumlah komentator telah berspekulasi tentang bagaimana Internet dapat mengubah kehidupan sehari-hari masyarakat, dan beberapa penelitian telah melihat pola penggunaan kelompok pengguna Internet yang tidak representatif, hanya sampel rumah tangga yang representatif secara nasional yang memungkinkan analis untuk membuat proyeksi tentang penggunaan Internet di masa depan dan kemungkinan konsekuensi (Nie \& Erbring, 2002).

Penerapan Internet dalam pendidikan dan E-learning memberikan dimensi baru pada proses pembelajaran dimana pengajaran tradisional cenderung modern dalam bentuk pembelajaran melalui berbagai sumber elektronik dengan internet dan komunitas virtual (Stošić \& Stošić, 2015). Meskipun prinsip-prinsip ini dapat diatasi tanpa teknologi, Internet menawarkan perancah yang kaya dan efisien bagi para pendidik untuk mengatasinya. Dengan demikian, banyak pendidik yang memasukkan Internet ke dalam kurikulum kelas mereka. Beberapa penelitian ada, bagaimanapun, yang menilai efektivitas bahan-bahan ini untuk mempromosikan praktik yang baik dalam pendidikan (Ritter \& Lemke, 2000). Misalnya, laboratorium komputer berbantuan internet yang digunakan untuk menambah dan memperkuat pengetahuan, untuk mengembangkan keterampilan proses yang terampil serta untuk mengembangkan sikap dan untuk mempraktekkan teori yang telah diberikan (Purnomo, 2003). Dengan demikian, mereka harus dapat mengambil manfaat dari berbagai teknologi komunikasi dan informasi dalam pekerjaan mereka dan mendorong peserta didik mereka untuk memanfaatkan teknologi ini sambil mengambil tanggung jawab belajar siswa di lingkungan belajar yang berpusat pada siswa. Internet dan teknologi informasi sangat cocok untuk digunakan dalam pendekatan yang berpusat pada peserta didik ( $\tilde{A}-z k a n$ \& $\mathrm{G} \tilde{A}^{1} / 4$ ler, 2018).

Di era internet, kecepatan penyebaran informasi dan bentuk penyajiannya telah berubah secara radikal. Bagaimana menemukan pengetahuan yang dibutuhkan dari sejumlah besar informasi adalah kualitas penting bagi pelajar modern (Jiang, 2018). 
Teknologi internet memungkinkan guru dan siswa untuk mengikuti pikiran mereka. Ini memungkinkan mereka mencoba ide-ide mereka sesegera mungkin untuk melayani proses belajar mengajar (Arsham, 1995). Modalitas pembelajaran online yang berbantuan internet menawarkan banyak peluang unik untuk metode pengajaran dan pembelajaran konstruktivis (Miller-First \& Ballard, 2017). Dalam paradigma konstruktivis, teknologi realitas virtual berfokus pada proses pembelajaran interaktif aktif pelajar dan upaya untuk mengurangi kesenjangan antara pengetahuan pebelajar dan pengalaman kehidupan nyata (Huang \& Liaw, 2018). Dengan pendekatan konstruktivis yang selaras sempurna, pebelajar akan berperilaku dan belajar secara berbeda. Untuk menangkap semua keragaman, diperlukan kerangka pembelajaran yang akan menghubungkan teori dengan praktik (Azlan dkk., 2020). Biggs, Kember, \& Leung (2001) mengungkapkan kerangka 3P (Presage-Process-Product) yang menggambarkan proses terjadinya belajar. Adapun 3P tersebut digambarkan ke dalam kerangka berikut.

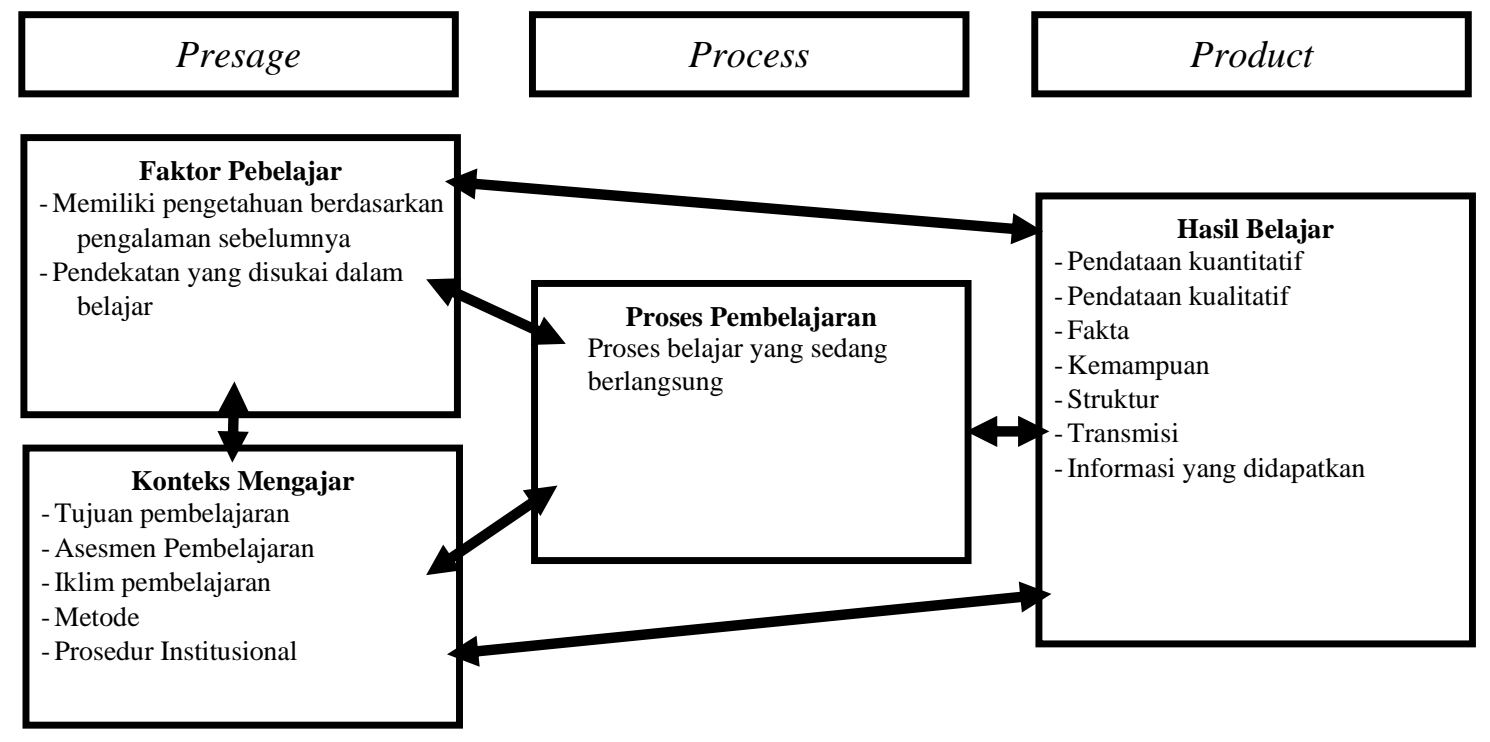

Gambar 1 Model 3P (Diadaptasi dari Biggs, Kember dan Leung, 2001)

Maka dari itu, penulis tertarik untuk meninjau terkait pemanfaatan internet dalam proses belajar mengajar yang dilakukan. Tulisan ini akan menyajikan bagaimana memanfaat internet untuk mendukung kegiatan pembelajaran yang efisien. Sajiannya meliputi (1) pemanfaatan sumber belajar digital, (2) filsafat aksiologi belajar dalam era digital dan (3) beberapa konstruksi menggunakan internet yang bisa digunakan mulai dari konstruksi media, konstruksi model maupun konstruksi metode dalam mendukung pembelajaran berbantuan internet.

\section{METODE}

Tulisan ini disajikan secara naratif dengan mengkaji berkaitan dengan pendayagunaan internet serta dikaitkan dengan aksiologi belajar pembelajaran di era digital. Tinjauan naratif ini bertujuan untuk memberikan gambaran penting tentang kesimpulan dari semua upaya sintesis ini (Orben, 2020). Pemilihan literatur dalam tulisan ini dilakukan secara acak dan disusun secara berkesinambungan. Adapun langkah-langkah dalam menyusun tulisan ini adalah (1) mencari topik yang berkenaan 
dengan kondisi dan situasi, (2) menyusun rancangan ide dan desain penulisannya, (3) melakukan pengumpulan dan cross check dan (4) menarik suatu kesimpulan

\section{HASIL PENELITIAN DAN PEMBAHASAN}

\section{Perkembangan Internet dalam Tatanan Dunia}

Adanya internet ini dilandasi pada pengembangan transistor sebelumnya oleh William Shockley, Walter Houser Brattain dan John Bardeen pada tahun 1947 (Lambert, Woodford, Poole, \& Moschovitis, 2005). Secara historis, internet pertama kali telah hadir sejak 1960-an yang dikembangkan di Amerika Serikat. Hadirnya internet bertepatan dengan perang dingin yang terjadi ketika dunia menjadi dua kutub, yakni Amerika Serikat dan Uni Soviet saling bersaing dalam memperluas pengaruh mereka di dunia, saling memandang dengan sangat hatihati dan curiga (Cohen-Almagor, 2013). Leonard Kleinrock di MIT menerbitkan makalah pertama tentang teori packet switching pada bulan Juli 1961 dan buku pertama pada subjek pada tahun 1964 (Kleinrock, 1961, 2007). Kleinrock meyakinkan Roberts (salah seorang pengurus DARPA) tentang kelayakan teoritis komunikasi menggunakan paket daripada sirkuit, yang merupakan langkah besar di sepanjang jalan menuju jaringan komputer. Langkah kunci lainnya adalah membuat komputer berbicara bersama (Leiner dkk., 2009). Pada akhir 1970-an, gagasan tentang internet (saat itu tidak diberi huruf kapital I) mulai muncul. Campbell-Kelly \& Garcia-Swartz (2013) menggambarkan situasi saat itu yang sedang terjadi persaingan antara monopoli telekomunikasi, produsen komputer, organisasi standar internasional - dan komunitas ARPANET - untuk mendefinisikan arsitektur Internet. Kontes ini masih belum terselesaikan, tetapi diberi kekuatan baru, dengan kedatangan personal computer yang terintegrasi dengan desktop pada 1980-an.

Internet berkembang pesat di Eropa dan Australia pada pertengahan hingga akhir tahun 1980-an (Segal, 2001). Sedangkan internet berkembang di Asia pada sekitar akhir tahun 1980-an dan awal tahun 1990-an (Chon, Konishi, Kanchanasut, \& Wong, 2006). Pada ulang tahunnya yang ke-25, Internet telah memiliki lebih dari 2 juta host dan berlipat ganda pada tahun 1995 (4 juta host). Internet bukan lagi sekedar jaringan yang mencakup Amerika dan Eropa, tetapi sudah mencakup seluruh belahan dunia, termasuk Indonesia (Darmawan, 2012). Internet yang masuk ke Indonesia pada fase awal krisis politik tahun 1990-an telah bangkit baik secara ekonomi maupun politik menjadi media alternatif yang mencari jalan keluar dari kendali negara (Hill \& Sen, 2000; Lim, 2002). Namun, Internet pada awalnya hanya tersedia untuk sebagian kecil masyarakat. Medianya masih sangat baru, belum matang, dan elitis (Lim, 2003). Perkembangan internet ini telah dilihat sebagai fenomena yang mendunia dan mempengaruhi berbagai bidang (Hill \& Sen, 2005).

\section{Aksiologi Belajar Pembelajaran Berbantuan Internet}

Teknologi Pendidikan merupakan disiplin keilmuan dalam memecahkan masalah pendidikan. Cara dalam memecahkan masalah pendidikan tersebut melalui serangkaian kegiatan memfasilitasi pembelajaran (facilitating learning) dan meningkatkan kinerja (improving performance) dengan adanya berbagai kajian secara etis dan praktis (Januszewski \& Molenda, 2013). Sebagai suatu disiplin keilmuan, teknologi pendidikan memiliki tiga karakteristik, yakni (1) pendekatan 
sistem, (2) pendayagunaan sumber belajar dan (3) orientasi pada pebelajar. Pendekatan sistem berarti berkenaan dengan rangkaian pola kegiatan pembelajaran yang dilakukan. Pendayagunaan sumber belajar berarti memanfaatkan atau menggunakan berbagai sumber-sumber yang ada untuk belajar. Sedangkan orientasi pada pebelajar berarti semua rangkaian pembelajaran haruslah berpihak pada pebelajar (Ibrahim, 1985). Maka, pemanfaatan internet merupakan salah satu alternatif yang dapat digunakan dalam proses pembelajaran untuk mendukung ketiga karakteristik tersebut untuk "mempermudah" perolehan pengetahuan.

Apabila ditinjau berdasarkan landasan falsafah, setiap pengetahuan, termasuk teknologi pendidikan, memiliki tiga komponen sebagai "tiang penyangga" pengetahuan yang didukungnya yang terdiri dari (1) ontologi (apa), (2) epistemologi (bagaimana) dan (3) aksiologi (untuk apa). Ontologi berarti penafsiran atau penelaahan terkait hakikat atau makna dari suatu objek. Epistemologi berarti cara bagaimana materi diperoleh dan disusun menjadi tubuh pengetahuan. Aksiologi berarti penggunaan pengetahuan yang telah diperoleh dan disusun dalam tubuh pengetahuan tersebut (Suriasumantri, 1984). Maka dari tinjauan tersebut, pemanfaatan internet dalam pembelajaran mengandung ketiga unsur tersebut, termasuk falsafah aksiologi.

Arif (2019) mengungkapkan bahwa pengetahuan-pengetahuan yang didapatkan manusia pada dasarnya dapat dikelompokkan menjadi dua, yaitu (1) terdapat yang masih atau hanya berupa ide atau konsep. Misalnya konsep tentang "orang", "binatang", dan sebagainya, dan (2) terdapat yang sudah berbentuk kalimat, pernyataan atau ungkapan, seperti kalimat "setiap yang bernyawa pasti akan mati", "air laut itu asin" dan sebagainya. Dengan pengetahuan yang dimilikinya, manusia selalu berusaha mencari kebenaran, kebahagiaan serta selalu ingin melakukan perubahan dalam berbagai aspek kehidupan (Arifin, 2013). Di samping itu dengan adanya pengetahuan, manusia merasa tidak puas terhadap karya budaya yang dimiliki dan selalu ingin melakukan inovasi atau pembaruan kehidupan (Lauer, 1991; Sztompka, 1993).

Aksiologi berfokus pada pertanyaan tentang apa yang 'seharusnya'. Ini berkaitan dengan sifat nilai dan berkaitan dengan pengajaran nilai-nilai moral dan pengembangan karakter (Tomar, 2014). Pertimbangan aksiologi dijalankan setelah adanya kegiatan yang bersifat ontologi dan epistomologi. Aksiologi mempertimbangkan terkait penggunaan dalam suatu pengetahuan yang telah diperoleh atau dikembangkan sebelumnya. Miarso (2004) memberikan gambaran terkait aksiologi dengan mencontohkan dibukanya SMP Terbuka (SMPT). Sesuai dengan falsafahnya, maka manfaat SMPT memungkinkan siswa untuk mengikuti pendidikan lanjut sesuai dengan kondisinya. Siswa SMPT masih dapat melaksanakan kegiatan sehari-hari untuk kelangsungan hidup keluarganya (misalnya membantu orang tua bekerja di sawah, mengurus adik di rumah dan sebagainya). Bagi pemerintah, penerapan ini memberikan perluasan kesempatan belajar bagi semua orang. Hal ini juga berlaku untuk pemanfaatan internet dalam dunia belajar pembelajaran.

Berdasarkan laporan yang berjudul "Digital 2021: the latest insights into the 'state of digital' pengguna internet di Indonesia pada tahun 2021 sebanyak 73,7 
persen dari total populasinya, yang berarti berjumlah 202,6 juta jiwa. Data ini menunjukkan perlu adanya "sokongan" baik dari pemerintah maupun guru dalam proses pembelajaran yang mampu memfasilitasi maupun meningkatkan kinerja belajar dari siswa melalui pendayagunaan internet. Mengenai siswa yang jelasjelas diterima sebagai pengguna internet yang bersemangat, penggunaan internet terutama untuk tujuan sosial dan hiburan karena revolusi internet tidak hanya terbatas pada pencarian informasi tetapi juga menyatukan orang. Namun, sangat jelas bahwa Internet tidak hanya menyediakan koneksi sosial dan hiburan, tetapi juga informasi akademis dan ilmiah. Oleh karena itu, sangat penting untuk mendorong siswa menggunakan sumber daya yang tak ternilai ini untuk mendapatkan informasi apapun yang mereka butuhkan dalam studi akademis mereka karena perkembangan Internet tidak akan ada artinya jika tidak digunakan dengan benar dalam pendidikan (Dogruer, Eyyam, \& Menevis, 2011).

Potensi internet ini sama halnya dengan gambaran dari Miarso (2004) pada paragraf sebelumnya. Bagi pemerintah, internet bermanfaat selain dalam memperbesar kesempatan belajar, juga memberikan efisiensi anggaran karena tidak lagi perlu membangun gedung-gedung sekolah yang terkadang memakan biaya yang cukup besar. Di samping itu, manfaat lain yang dapat dirasakan adalah membangun kurikulum yang tidak lagi bersifat top-down atau cenderung berpusat pada pemerintah, namun cenderung akan berpusat pada daerahnya masingmasing atau desentralisasi. Pemerintah memiliki peranan besar dalam perumusan kebijakan dan pembuatan peraturan perundang-undangan untuk diterapkan di seluruh Indonesia. Ada baiknya pemerintah mempertimbangkan pemberian kebijakan otonomi pendidikan pada masing-masing daerah. Alasan utamanya adalah karakteristik pada masing-masing daerah yang sangat beragam yang dapat dilihat dari berbagai sisi, sehingga dimungkinkan rekomendasi untuk membentuk tim kurikulum lokal. Maka dari itu Bruner (1966) mengungkapkan bahwa tim kurikulum lokal memiliki peranan yang jelas dalam penjabaran kegiatan pembelajaran di kelas dan media (internet) yang bisa digunakan. Nantinya dari tim inilah yang akan memberikan keputusan berkenaan bagaimana yang seharusnya dilakukan agar pembelajaran bisa maksimal, khususnya dalam memaksimalkan teknologi internet di daerah-daerah dengan karakteristik yang beragam.

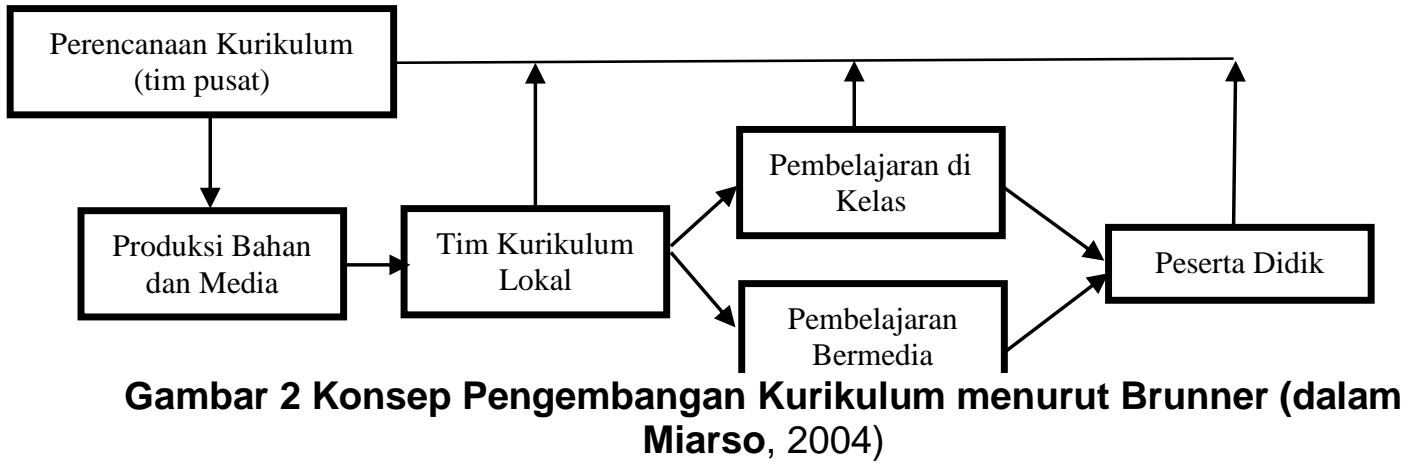

Di samping adanya manfaat yang diperoleh pemerintah, guru juga dapat mengambil manfaat dari adanya internet yang didayagunakan untuk mengajar. Karena guru merupakan panutan yang menentukan kualitas sumber daya manusia di masa depan. Sehingga perlu adanya peningkatan kinerja guru. Lima aspek 
yang perlu diperhatikan (1) kualitas kerja berkaitan langsung dengan kemampuan guru menguasai segala hal yang berkaitan dengan proses pembelajaran, yang terdiri dari materi pelajaran, pengelolaan belajar mengajar dan pengelolaan kelas, (2) kecepatan atau ketepatan kerja, merupakan indikator yang berkaitan dengan penggunaan media pembelajaran yang sesuai dengan isi materi pembelajaran, bahkan berhubungan langsung dengan ketepatan guru dalam merencanakan program pembelajaran dengan waktu yang tersedia, (3) inisiatif dalam bekerja, merupakan kemampuan guru, memimpin kelas, mengelola interaksi belajar mengajar di kelas dengan baik, dan menilai hasil belajar siswa, (4) kemampuan kerja, dapat dilihat dari indikator kemampuan guru yang meliputi penggunaan berbagai metode dalam pembelajaran, pemahaman dan pelaksanaan fungsi serta layanan bimbingan konseling kepada siswa yang membutuhkan bimbingan dan arahan, (5) komunikasi dalam indikator ini guru diharapkan mampu berbicara dengan baik, memahami dan mengelola administrasi sekolah, serta mengembangkan kemampuannya (Fitria, 2018). Adanya internet dapat membantu meningkatkan performansi-performansi guru tersebut dalam membelajarkan kepada siswa. Contoh gambaran sederhananya adalah pada perumusan tujuan pembelajaran, guru menggunakan internet untuk mengidentifikasi karakteristik belajar siswa. Pada proses pembelajaran guru menggunakan Learning Management Systems (LMS) sebagai wadah dalam mengelola pembelajaran yang tersambung dengan jaringan internet. Pada proses evaluasi guru menggunakan berbagai asesmen digital agar nilai yang diperoleh siswa dapat masuk ke dalam data guru secara digital. Proses-proses ini tentunya menjadikan guru lebih efektif dalam mengajar. Di samping itu, secara tidak langsung guru akan belajar tentang bagaimana mengoperasikan atau mengelola pembelajaran secara digital dengan bantuan internet. Pola pembelajaran ini termasuk ke dalam golongan pola pembelajaran guru dengan media, di mana sumber utama yang digunakan bukan lagi terpusat pada guru, namun menggunakan media untuk menyajikan isi materi. Guru berperan dalam lebih penting dari sekadar menyajikan materi, seperti memberikan motivasi, membantu kesulitan belajar yang dialami oleh siswa dan lain sebagainya (Abidin, 2016).

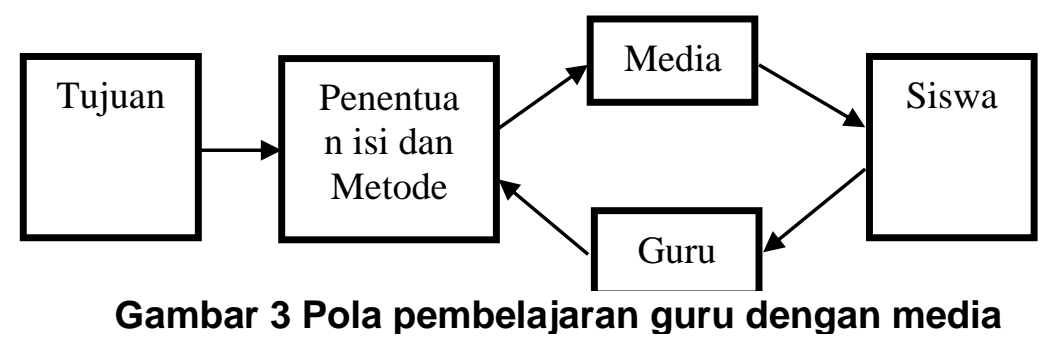

Manfaat ini juga dirasakan bagi siswa sebagai subjek belajar yang terlibat dalam proses pembelajaran. Bora \& Ahmed (2013) mengungkapkan siswa dapat mengambil kelas online, menghadiri ujian online, mendapatkan umpan balik tentang kelas dari instruktur, dan mengirimkan proyek dan tugas mereka secara online kepada guru mereka tanpa harus bertatap muka. Di samping itu, Lee (2003) menambahkan kelas internet dapat digunakan dalam model belajar mengajar yang terintegrasi untuk memfasilitasi strategi pembelajaran yang aktif, atau lebih 
sederhana sebagai alat pendukung konten untuk menyampaikan materi dan informasi dalam bentuk digital seperti teks bacaan yang diperlukan dan catatan pembelajaran. Dalam penelitiannya, pengalaman pribadi serta evaluasi siswa terhadap modul menunjukkan bahwa pembelajaran web yang terintegrasi internet dapat menambah nilai pada pengalaman belajar dan mengajar dan dapat berkontribusi secara signifikan untuk pengembangan keterampilan intelektual dan pribadi yang diperlukan. Hal ini berpotensi membangun pembelajaran secara mandiri kepada siswa, sehingga berorientasi pada student-centered learning.

Untuk mewujudkan berbagai manfaat internet tersebut, kunci utama terletak pada fondasi kebijakan yang diterapkan oleh pemerintah. Laman dari Internet Society menjelaskan terdapat lima prioritas yang perlu untuk dilakukan. Lima prioritas tersebut yakni (1) akses dan infrastruktur, (2) visi dan kebijakan, (3) inklusif, (4) kapasitas dan (5) konten dan perangkat.

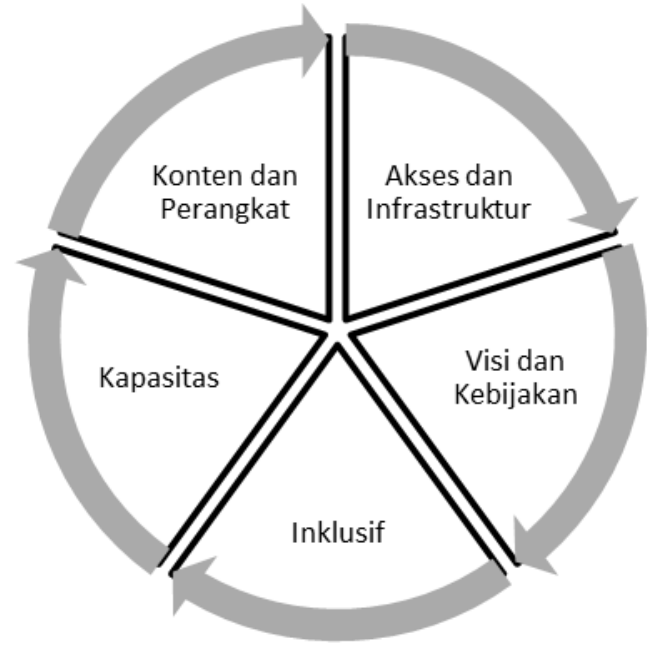

\section{Gambar 4 Lima prioritas Internet dalam Pendidikan}

Pada prioritas akses dan infrastruktur yang berarti peningkatan infrastruktur broadband untuk meningkatkan kualitas internet pada suatu daerah serta mendukung keperluan sekolah terhadap perangkat digital, seperti tablet, komputer dan sebagainya. Pada prioritas visi dan kebijakan berkenaan dengan peningkatan akses internet di berbagai jenjang dari tingkat dasar hingga perguruan tinggi. Pada prioritas inklusif dapat membantu pelayanan yang inklusif dengan bantuan internet, bahkan dapat mengembangkan lifelong learning bagi orang dewasa atau juga mengembangkan instrumen pembelajaran bagi penyandang berkebutuhan khusus. Semua itu sangat mungkin dengan adanya bantuan internet di dalamnya. Pada prioritas kapasitas, adanya internet juga membantu meningkatkan kemampuan dari pebelajar dalam pengembangan personalnya. Sedangkan pada prioritas konten dan perangkat, internet membantu akses dalam pemerolehan konten pembelajaran yang menarik. Dalam hal ini contohnya siswa dapat menggunakan layanan MOOCs ataupun Sumber Belajar Terbuka (OER). Maka, penyediaan layanan ini di samping dikembangkan oleh sekolah, namun juga dari pemerintah ada baiknya untuk mewadahi layanan ini. Jadi, siswa bisa belajar tidak hanya terpaku pada satu konten yang disediakan, namun berbagai konten yang secara luas tersebar di dunia maya 


\section{KESIMPULAN}

Penggunaan internet dalam pembelajaran pada prinsipnya memiliki tujuan untuk memfasilitasi pembelajaran maupun peningkatan kinerja sebagaimana yang terang disebutkan dalam definisi teknologi pendidikan. Karena sejak kehadirannya, proses pembelajaran dengan adanya bantuan dari internet mampu memberikan efektivitas maupun efisiensi dalam belajar mengajar. Manfaat tersebut dirasakan oleh berbagai pihak, termasuk pemerintah, guru dan siswa. Bagi pemerintah, adanya internet mampu memberikan perluasan kesempatan belajar hingga efisiensi anggaran. Bagi guru adanya internet mampu memberikan efektivitas mulai dari tahap perencanaan, implementasi hingga evaluasi yang dapat diminimalisir kegiatannya dengan teknologi digital. Bagi siswa yang merupakan subjek belajar, internet mampu mengembangkan fleksibilitas, kemampuan intelektual hingga personal secara mandiri. Untuk itu, pemerintah selaku pemangku kebijakan direkomendasikan untuk memberikan prioritas pembangunan internet di berbagai daerah untuk mendukung manfaat-manfaat tersebut.

\section{REFERENSI}

Abidin, Z. (2016). Pengembangan Sumber Belajar. Malang: Universitas Negeri Malang.

Arif, S. (2019). Prinsip-Prinsip Dasar Epistemologi Islam. Dalam A. Husaini, Filsafat IImu: Perspektif Barat dan Islam. Depok: Gema Insani.

Arifin. (2013). Penelitian Pendidikan: Pendekatan Kuantitatif dan Kualitatif. Bantul: Lilin Persada Press.

Arsham, H. (1995). Interactive education: Impact of the internet on learning \& teaching. Research and Development, 42(2), 7-19.

Ã-zkan, Y., \& GÃ¹/4ler, S. (2018). Podcast Applications in Pre-service Language Teacher Education from a Constructivist Perspective. World Journal on Educational Technology: Current Issues, 10(3), 131-141.

Azlan, C. A., Wong, J. H. D., Tan, L. K., A.D. Huri, M. S. N., Ung, N. M., Pallath, V., ... $\mathrm{Ng}$, K. H. (2020). Teaching and learning of postgraduate medical physics using Internet-based e-learning during the COVID-19 pandemic - A case study from Malaysia. Physica Medica, 80, 10-16. doi:

Biggs, J., Kember, D., \& Leung, D. Y. (2001). The revised two-factor study process questionnaire: R-SPQ-2F. British journal of educational psychology, 71(1), 133-149.

Bora, U. J., \& Ahmed, M. (2013). E-learning using cloud computing. International Journal of Science and Modern Engineering, 1(2), 9-12.

Bruner, J. S. (1966). Toward a Theory of Instruction. Harvard University Press.

Campbell-Kelly, M., \& Garcia-Swartz, D. D. (2013). The history of the internet: The missing narratives. Journal of Information Technology, 28(1), 18-33. 
Chon, K., Konishi, K., Kanchanasut, K., \& Wong, L. (2006, Februari). Internet History in Asia. Dipresentasikan pada 16th APAN Meetings / Advanced Network Conference, Busan. Diambil dari https://web.archive.org/web/20060201035514/http://apan.net/meetings/busan 03/cs-history.htm

Cohen-Almagor, R. (2013). Internet history. Dalam Moral, ethical, and social dilemmas in the age of technology: Theories and practice (hlm. 19-39). IGI Global.

Curran, J., Fenton, N., \& Freedman, D. (2016). Misunderstanding the internet. Routledge.

Darmawan, A. (2012). Sejarah internet. Jurnal Pendidikan Sejarah, 12(12).

Digital 2021: The latest insights into the 'state of digital.' (2021, Januari 27). Diambil 11 Juli 2021, dari We Are Social website: https://wearesocial.com/blog/2021/01/digital-2021-the-latest-insights-into-thestate-of-digital

Dogruer, N., Eyyam, R., \& Menevis, I. (2011). The use of the internet for educational purposes. Procedia-Social and Behavioral Sciences, 28, 606-611.

Fitria, H. (2018). The Influence Of Organizational Culture And Trust Through The Teacher Performance In The Private Secondary School In Palembang. International Journal of Scientific \& Technology Research, 7(7).

Gray, J., \& Rumpe, B. (2015). Models for digitalization. Software \& Systems Modeling, 14(4), 1319-1320.

Hagberg, J., Sundstrom, M., \& Egels-Zandén, N. (2016). The digitalization of retailing: An exploratory framework. International Journal of Retail \& Distribution Management, 44(7), 694-712.

Hill, D. T., \& Sen, K. (2000). The Internet in Indonesia's new democracy. Democratization, 7(1), 119-136.

Hill, D. T., \& Sen, K. (2005). The Internet in Indonesia's New Democracy. London: Routledge.

Huang, H.-M., \& Liaw, S.-S. (2018). An analysis of learners' intentions toward virtual reality learning based on constructivist and technology acceptance approaches. International Review of Research in Open and Distributed Learning, 19(1).

Ibrahim. (1985). Pengantar Teknologi Pendidikan (I. W. Ardhana, Ed.). Malang: IKIP Malang.

Internet Society. (2017). Internet Access and Education: Key considerations for policy makers. Diambil 12 Juli 2021, dari Internet Society website: https://www.internetsociety.org/resources/doc/2017/internet-access-andeducation/ 
Januszewski, A., \& Molenda, M. (2013). Educational technology: A definition with commentary. Routledge.

Jiang, Y. (2018). The effective application of fragmented learning guided by constructivism. vol, 3, 10-13.

Kleinrock, L. (1961). Information flow in large communication nets. RLE Quarterly Progress Report, 1.

Kleinrock, L. (2007). Communication nets: Stochastic message flow and delay. Courier Corporation.

Lambert, L., Woodford, C., Poole, H., \& Moschovitis, C. J. P. (Ed.). (2005). The Internet: A Historical Encyclopedia. Santa Barbara, Calif: ABC-CLIO.

Lauer, R. H. (1991). Perspectives on Social Change (Subsequent edition). Boston: Allyn \& Bacon.

Lee, D. (2003). New Technologies in the Politics Classroom: Using Internet Classrooms to Support Teaching and Learning. Politics, 23(1), 66-73.

Legner, C., Eymann, T., Hess, T., Matt, C., Böhmann, T., Drews, P., ... Ahlemann, F. (2017). Digitalization: Opportunity and Challenge for the Business and Information Systems Engineering Community. Business \& Information Systems Engineering, 59(4), 301-308.

Leiner, B. M., Cerf, V. G., Clark, D. D., Kahn, R. E., Kleinrock, L., Lynch, D. C., ... Wolff, S. (2009). A brief history of the Internet. ACM SIGCOMM Computer Communication Review, 39(5), 22-31.

Lim, M. (2002). Cyber-civic space in Indonesia: From panopticon to pandemonium? International development planning review, 24(4), 383.

Lim, M. (2003). The Internet, social networks, and reform in Indonesia. Contesting media power: Alternative media in a networked world, 273-288.

Miarso, Y. (2004). Menyemai benih teknologi pendidikan. Jakarta: Kencana.

Miller-First, M. S., \& Ballard, K. L. (2017). Constructivist teaching patterns and student interactions. Internet Learning Journal, 6(1), 25-32.

Nie, N. H., \& Erbring, L. (2002). Internet and society: A preliminary report. IT \& society, 1(1), 275-283.

Orben, A. (2020). Teenagers, screens and social media: A narrative review of reviews and key studies. Social Psychiatry and Psychiatric Epidemiology, 55(4), 407414.

Parida, V. (2018). Digitalization. Dalam Addressing Societal Challenges (hlm. 23-38). Luleå University of Technology. Diambil dari http://urn.kb.se/resolve?urn=urn:nbn:se:Itu:diva-68008 
Purnomo, A. (2003). Pemanfaatan internet sebagai media pembelajaran di MTs Negeri 1 Malang (Diploma, Universitas Negeri Malang). Universitas Negeri Malang. Diambil dari http://repository.um.ac.id/867/

Ritter, M. E., \& Lemke, K. A. (2000). Addressing the'seven principles for good practice in undergraduate education'with internet-enhanced education. Journal of geography in Higher Education, 24(1), 100-108.

Segal, B. (2001). A Short History of Internet Protocols at CERN. CERN computer newsletter.

Stošić, L., \& Stošić, I. (2015). Perceptions of teachers regarding the implementation of the internet in education. Computers in Human Behavior, 53, 462-468.

Suriasumantri, J. S. (1984). Filsafat ilmu: Sebuah pengantar populer. Sinar Harapan.

Sztompka, P. (1993). The Sociology of Social Change (1st edition). Oxford, UK; Cambridge, Mass: Wiley-Blackwell.

Tomar, B. (2014). Axiology in teacher education: Implementation and challenges. IOSR Journal of Research \& Method in Education, 4(2), 51-54.

(C) 2021 by the authors. Submitted for possible open access publication under the terms and conditions of the Creative Commons Attribution (CC $\quad$ BY $\quad$ SA) license (https://creativecommons.org/licenses/by-sa/4.0/). 